\title{
Anatomy of the Middle Meningeal Artery
}

\section{Anatomia da artéria meníngea média}

\author{
Marco Aurélio Ferrari Sant'Anna ${ }^{10}$ Leonardo Luca Luciano ${ }^{2}$ Pedro Henrique Silveira Chaves ${ }^{3}$ \\ Leticia Adrielle dos Santos ${ }^{4}$ Rafaela Gonçalves Moreira ${ }^{5}$ Rian Peixoto ${ }^{6}$ Ronald Barcellos ${ }^{7,8}$ \\ Geraldo Avila Reis 7,8 Carlos Umberto Pereira ${ }^{8} \quad$ Nícollas Nunes Rabelo ${ }^{9}$
}

${ }^{1}$ Hospital Celso Pierro, Pontifícia Universidade Católica de Campinas, Campinas, SP, Brazil

2 School of Medicine, Universidade Federal de Alfenas, Alfenas, MG, Brazil

${ }^{3}$ Centro Universitário Atenas, Paracatu, MG, Brazil

${ }^{4}$ Universidade Federal do Sergipe, Aracaju, SE, Brazil

${ }^{5}$ Faculdade Atenas, Passos, MG, Brazil

${ }^{6}$ School of Medicine, Faculdade Santa Marcelina, São Paulo, SP, Brazil

${ }^{7}$ Neurosurgery Department of the Hospital de Urgência de Sergipe Governador João Alves Filho, Aracaju, SE, Brazil

\author{
Address for correspondence Nicollas Nunes Rabelo, MD, Department \\ of Neurosurgery, Faculdade Atenas, Passos, Minas Gerais, Rua Oscar \\ Cândido Monteiro, 1000, jardim Colégio de Passos, Passos, MG, \\ 37900, Brazil (e-mail: nicollasrabelo@hotmail.com). \\ 8 Neurosurgery Department of the Fundação de Beneficência \\ Hospital de Cirurgia Aracaju, SE, Brazil \\ ${ }^{9}$ Neurosurgery Department, Neurosurgery Service of HGUSE and \\ the Benefit Foundation Hospital of Surgery, Aracaju, SE, Brazil \\ 10 Department of Neurosurgery, Faculdade Atenas, Passos, MG, Brazil
}

Arq Bras Neurocir 2021;40(4):e339-e348.

\begin{abstract}
Keywords

- neurosurgery

- neuroanatomy

- middle meningeal artery

- meningeal artery

Introduction The middle meningeal artery (MMA) is an important artery in neurosurgery. As the largest branch of the maxillary artery, it provides nutrition to the meninges and to the frontal and parietal regions. Diseases, including dural arteriovenous fistula (DAVF), pseudoaneurysm, true aneurysm, traumatic arteriovenous fistula (TAVF), Moya-Moya disease (MMD), recurrent chronic subdural hematoma (CSDH), migraine, and meningioma, may be related to the MMA. The aim of the present study is to describe the anatomy of the MMA and to correlate it with brain diseases.

Methods A literature review was performed using the PubMed, Scielo, Scientific Direct, Ebsco, LILACS, TripDataBase and Cochrane databases, with the following descriptors: neurosurgery, neuroanatomy, meninges and blood supply.

Discussion The MMA is embedded in a cranial groove, and traumatic or iatrogenic factors can result in MMA-associated pseudoaneurysms or arteriovenous fistulas (AVFs). In hemodynamic stress, true aneurysms can develop. Arteriovenous fistulas, pseudoaneurysms, and true aneurysms can be effectively treated by endovascular or surgical removal. In MMD, the MMA plays a role in the development and in the improvement of collateral circulation. Finally, in cases of $\mathrm{CSDH}$, when standard surgery and drainage fail, MMA embolization can constitute a great alternative.

Conclusion The MMA is a relevant structure for the understanding of neurosurgical diseases. In conclusion, every neurosurgeon must know the anatomy of the MMA sufficiently to correlate it with the diagnosed pathology, thus obtaining treatment effectiveness and preventing brain lesion.
\end{abstract}

received

May 26, 2020

accepted

March 9, 2021

published online

August 3, 2021
DOI https://doi.org/ 10.1055/s-0041-1733863. ISSN 0103-5355.

\footnotetext{
(c) 2021. Sociedade Brasileira de Neurocirurgia. All rights reserved. This is an open access article published by Thieme under the terms of the Creative Commons Attribution-NonDerivative-NonCommercial-License, permitting copying and reproduction so long as the original work is given appropriate credit. Contents may not be used for commercial purposes, or adapted, remixed, transformed or built upon. (https://creativecommons.org/ licenses/by-nc-nd/4.0/) Thieme Revinter Publicações Ltda., Rua do Matoso 170, Rio de Janeiro, RJ, CEP 20270-135, Brazil
} 


\section{Resumo}

\section{Palavras-chave \\ - neurocirurgia \\ - neuroanatomia \\ - artéria meníngea média \\ - artéria meníngea}

Introdução A artéria meníngea média (AMM) se configura como um importante vaso arterial na neurocirurgia. É o maior ramo da artéria maxilar e fornece nutrição às meninges e às regiões frontal e parietal. Doenças, incluindo fístula arteriovenosa dural (FAVD), pseudoaneurisma, aneurisma verdadeiro, fístula arteriovenosa traumática (FAVT), doença de Moya-Moya (DMM), hematoma subdural crônico (HSDC) recorrente, migrânea e meningioma podem estar relacionadas à AMM. O objetivo do presente estudo é descrever a anatomia da AMM e sua correlação com as doenças envolvidas. Métodos Uma revisão da literatura foi realizada utilizando as bases de dados PubMed, Scielo, Scientific Direct, Ebsco, LILACS, TripDataBase e Cochrane, com os seguintes descritores: neurocirurgia, neuroanatomia, meninges e irrigação sanguínea.

Discussão A AMM está inserida em um sulco do crânio, e fatores traumáticos ou iatrogênicos podem resultar em pseudoaneurismas ou em fístulas arteriovenosas (FAVs) associadas. Quando o estresse hemodinâmico aumenta, aneurismas verdadeiros podem se desenvolver. Fístulas arteriovenosas, pseudoaneurismas e aneurismas verdadeiros podem ser efetivamente tratados por remoção endovascular ou de forma cirúrgica. Na DMM, a AMM desempenha um papel muito importante no desenvolvimento e na compensação da circulação colateral. Em casos de HSDC recidivante, quando a cirurgia convencional e drenagem falham, a embolização da AMM pode ser uma ótima opção.

Conclusão A AMM é uma estrutura anatômica importante no entendimento das doenças neurocirúrgicas. Portanto, todo neurocirurgião deve conhecer a anatomia da AMM e estar apto a correlacioná-la com a patologia envolvida, obtendo, assim, efetividade no tratamento e prevenção de lesão cerebral.

\section{Introduction}

The middle meningeal artery (MMA) is the larger of the two terminal branches of the external carotid artery, and it is a significant branch of the internal maxillary artery. It is responsible for the nutrition of the meninges, as well as of the temporal and parietal regions. Its anatomy plays a role in the planning of endovascular and surgical interventions in the skull base. Due to its complex embryology, it is expected that anatomical variations and anomalies may occur. In fact, anomalies and variations of the origin, the branches and the position of the MMA have been well-documented in the literature. ${ }^{1-3}$ Since these anatomy vaiation show clinical importance in cases of fractures in the skull base, of bypass procedures and of epidural hematomas, ${ }^{4}$ they should be considered in the diagnosis and treatment of pathologies that affect the MMA., ${ }^{5,6}$ Accordingly, Kresimir Lukic et al. reported that the knowledge about the anatomical position and branches of the MMA is extremely important in radiology and surgery. ${ }^{7}$

Considering its unique anatomical characteristics and its exposure at the temporal bone region, the MMA is vulnerable to skull damage that results in the development of posttraumatic pseudoaneurysm or epidural bleeding. ${ }^{8}$ Some large extracerebral vessels and the MMA (or its branches) are involved in the mechanisms that associate migraine with arterial vasodilation or neurogenic inflammation and explain migraine-associated headache. ${ }^{9,10}$ Other diseases that may affect the MMA are aneurysm, recurrent chronic sub- dural hematoma, dural arteriovenous fistula (DAVF), traumatic arteriovenous fistula (TAVF), and Moya-Moya disease (MMD). ${ }^{11,12}$ Therefore, detailed and precise knowledge of the anatomy of the MMA is essential to support neurosurgical, neuroendoscopic, and neurovascular approaches. Therefore, the main objective of the present study is to review this knowledge under the clinical perspective.

\section{Methods}

To achieve the main goal, the present study employed a literature review using the following databases: PubMed, Scielo, Scientific Direct, Ebsco, LILACS, TripDataBase and Cochrane. The descriptors used were: middle meningeal artery, neurosurgery, neuroanatomy, dura mater, and blood supply. A total of 68 articles that met the inclusion criteria of being published between 1896 and 2017 were selected. The images were made in Adobe Photoshop CC 2019, version 20.0.10 (Adobe, San Jose, CA, USA), and our team drew by hand the figures representing the anatomy of the MMA.

\section{Discussion}

\section{Anatomical Description and its Variations}

The meningeal arteries comprise arterial branches that rise up between the dura mater and the bone, supplying both structures. There are three meningeal arteries: posterior (PMA), middle (MMA), and anterior (AMA) ( - Fig. 1, — Fig. 2). The AMA 


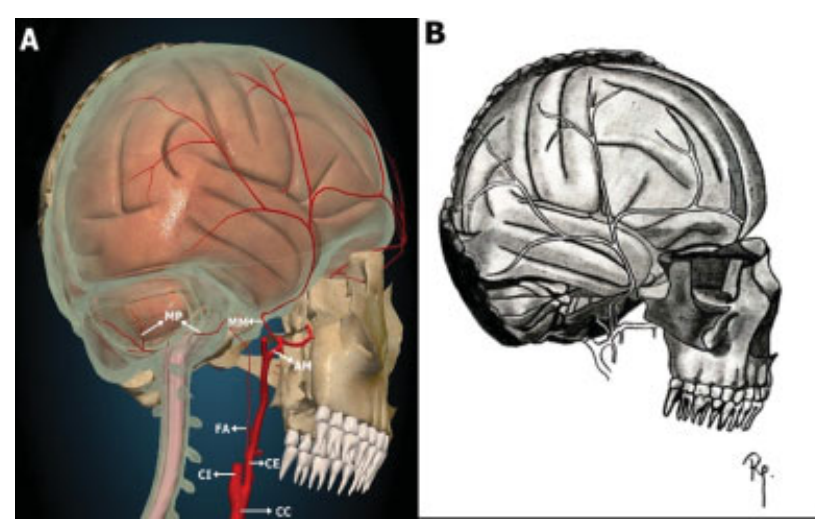

Fig. 1 Skull lateral view highlighting the temporal fossa. The frontal, occipital, parietal and temporal bones were omitted, and the dura mater is represented by the gray shading in figure A. (A) representative 3D cranial image obtained from an oblique view showing vascularization (in red) by the middle meningeal artery (MM) and its branches, as well as by the external carotid artery (CE) ramifications. The MM is a branch of the maxillary artery (AM), and the posterior meningeal artery (MP) is a branch of the FA (ascending pharyngeal artery); (B) - representative $2 \mathrm{D}$ drawing of the MM and its branches, from a coronal view. CC: common carotid artery; $\mathrm{Cl}$ : internal carotid artery; CE: external carotid artery; FA: ascending pharyngeal artery; AM: maxillary artery; MM: middle meningeal artery; FA: posterior meningeal artery.

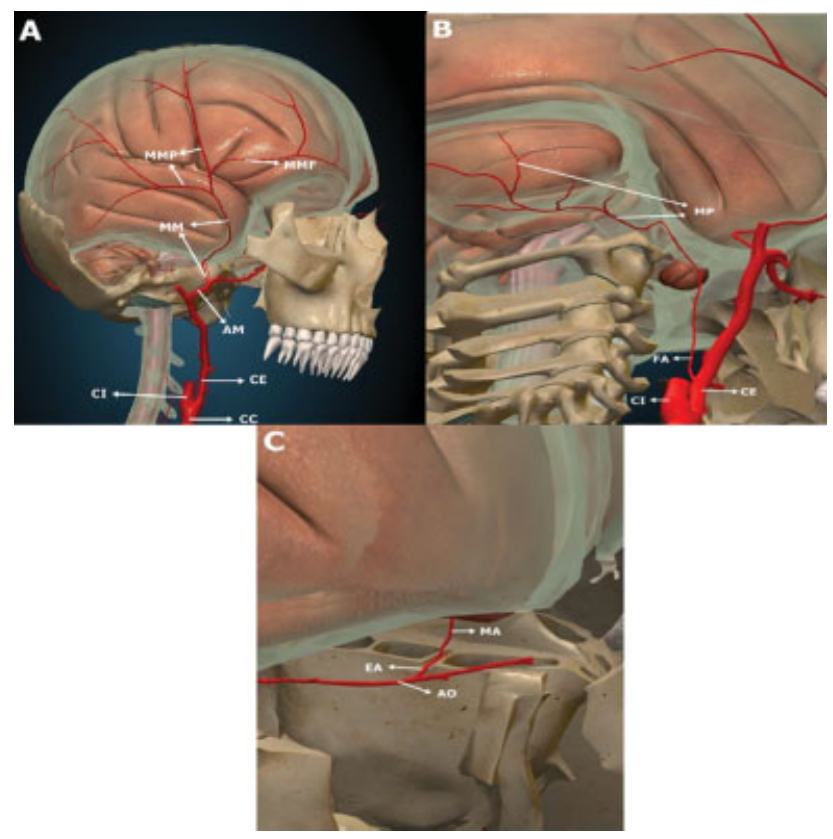

Fig. 2 Represents the anterior, middle and posterior meningeal artery. (A) - Side view. Middle meningeal artery and its frontal and parietal branches. (B) - Lateral-inferior view. Posterior meningeal artery and its vascular territory. The MP artery is a branch of the FA. (C) - Front view. Evidence of ethmoid bone (anterior ethmoidal cells). Anterior meningeal artery. which is a branch of the EA.CC: common carotid artery; $\mathrm{Cl}$ : internal carotid artery; $\mathrm{CE}$ : external carotid artery; AM: maxillary artery; MM: middle meningeal artery; MMF: middle meningeal frontal branch; MMP: middle meningeal artery parietal branch. AF: ascending pharyngeal artery; MP: posterior meningeal artery; AO: ophthalmic artery; EA: anterior ethmoidal artery; MP: anterior meningeal artery. originates from the anterior ethmoidal artery and supplies a short region on the Galli crest ${ }^{13-15}$ ( - Fig. 2C). The PMA starts from the vertebral, ascending occipital or pharyngeal arteries, ${ }^{15}$ and supplies the medial portions of the dura of the posterior fossa, the cerebellar sickle, the posterior segment of the brain scythe, and the adjacent tentorium. The MMA, in turn, irrigates a greater surface of the occipital, parietal, frontal, and temporal regions (-Fig. 2B).

The maxillary artery consists of a primary terminal branch of the external carotid artery ${ }^{16}$ and originates posteriorly to the mandibular branch. The MMA is the most common branch of the mandibular segment of the maxillary artery and originates at a variable distance from the external carotid artery and the superficial temporal artery ${ }^{17}$ (-Fig. 2A, - Fig. 3A). The MMA then irrigates the cranial dura mater and, via its perforating branches, provides blood supply to the periosteum of the inner lamina of the cranial bones. ${ }^{18}$ After entering the middle cranial fossa, the MMA performs a right-angled curve to assume a horizontal course, and then runs forward and laterally through the floor of the lateral piece of the middle cranial fossa, the dura, and the inner part of the cranial vault ${ }^{17,19,20}$ (-Fig. 3A, - Fig. 3B).

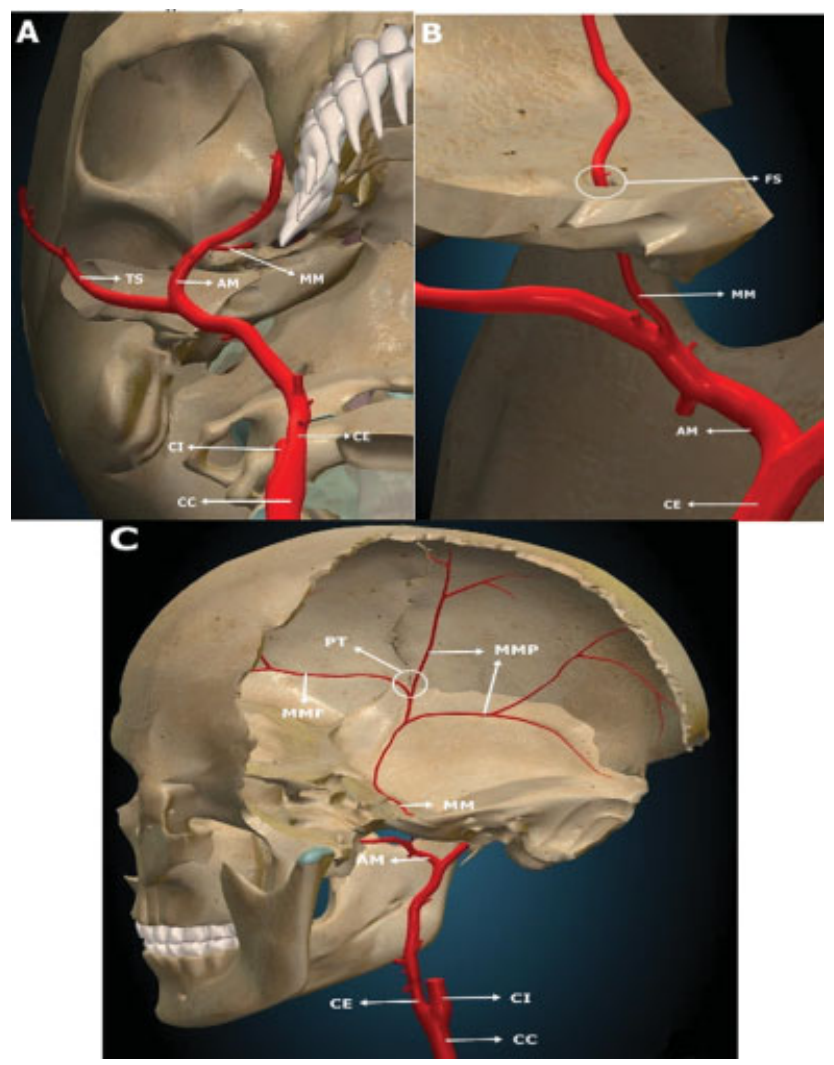

Fig. 3 Middle meningeal artery pathway without anatomical variation. Figure shows contact with bone projections. (A) - Bottom view. (B) - penetration of the middle meningeal artery into the skull by the spinous shape (FS), extracranial, intraosseous and intracranial portion. The MM issues two branches, MMP and MMF. TS is a branch of AM. (C) - relationship between the middle meningeal artery and the pterio (PT). CC: common carotid artery; $\mathrm{Cl}$ : internal carotid artery; $\mathrm{CE}$ : external carotid artery; AM: maxillary artery; MM: middle meningeal artery; TS: superficial temporal artery; MMP: middle meningeal artery parietal branch; MMF: middle meningeal artery frontal branch. 
The MMA then changes its path after reaching the pterion mark, extending by the inner area of the frontal and parietal bones ( - Fig. $\mathbf{3 C}$ ). The second change in its course may occur at the bone canal or groove on the pterion of the cerebral surface. ${ }^{17}$ Therefore, the MMA can be divided into interosseous, extracranial, and intracranial segments (-Fig. 3B). The extracranial portion of the MMA runs superiorly from its origin and reaches medially the external face of the skull base, following a right course in most cases. It is worth reminding that the dura mater does not attach to this segment (-Fig. 4, - Fig. 5). The intraosseous portion of the MMA extends by the outer and inner orifices of the foramen spinosum of the higher wing of the sphenoid bone, crossing it. Finally, the intracranial segment of the MMA is observed after the artery enters the skull. This portion is characterized as the origin for most MMA branches, and arises in the surface of the middle cranial fossa, opposite to the pterion ${ }^{8}$ (-Fig. 3C, -Fig. 4, -Fig. 5, -Fig. 6).

This anatomical description is important to identify variations that affect the extracranial ( - Fig. 7A, 7B) and intracranial MMA branches portions (-Fig. 8A, 8B, 8C). After MMA extension through the foramen spinosum, the petrous branch goes through the canal of the greater petrous nerve, being basically divided into two branches: 1 ) the medial or cavernous branch, which contributes to irrigate the Gasser ganglion, the third portion of the trigeminal nerve and the dura mater around the foramen ovale, thus having an essential involvement in the origin of dural fistulas in cavernous sinus region ${ }^{18}$; and 2 ) the basal tentorial branch, which irrigates the cerebellum tent and may underlie dural fistulas of the lateral sinus, even irrigating tumors located in the

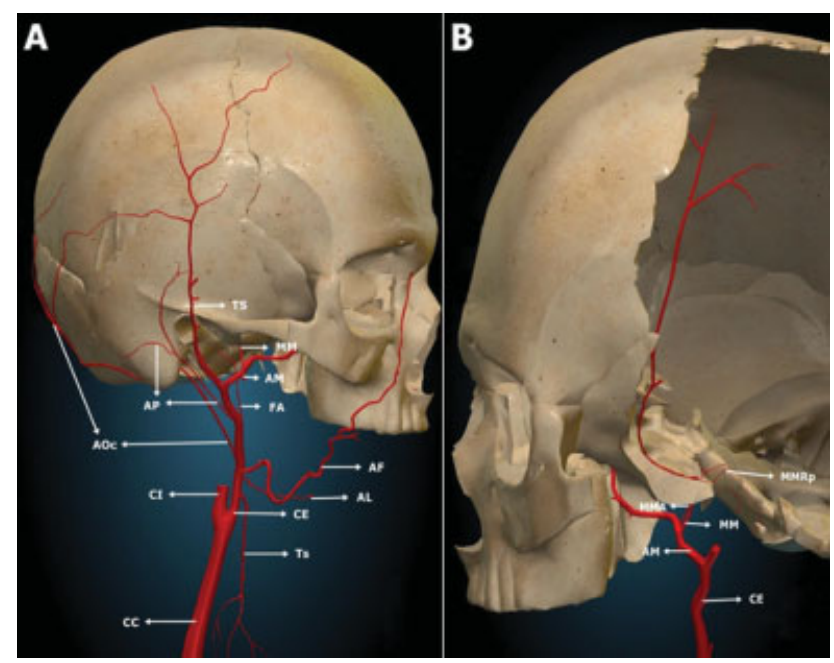

Fig. 4 Representation of the external carotid artery and its branches. (A) - Side view. (B) - Latero-posterior view. Evidence is MM, which is a branch of AM and MMRp, derived from MM. CC: common carotid artery; $\mathrm{Cl}$ : internal carotid artery; CE: external carotid artery; Ts: superior thyroid artery; AL: lingual art; AF: facial artery; AF: ascending pharyngeal artery; AP: posterior auricular artery; AOc: occipital artery; TS: superficial temporal artery; AM: maxillary artery; MM: middle meningeal artery. B: Latero-posterior view. MMA: accessory middle meningeal artery; MMRp: middle meningeal artery petrous branch.

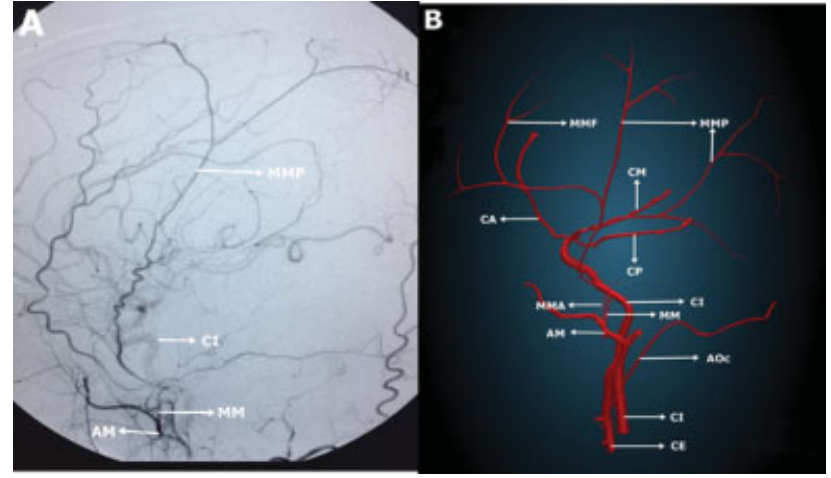

Fig. 5 Side view. (A) - arteriography showing branches of the external carotid artery. Evidence for MM and MMP that are branches of AM. Topographic view of $\mathrm{Cl}$. (B) - 3D schematic drawing in the topography of the arteriography of figure $\mathrm{A}$. $\mathrm{Cl}$ : internal carotid artery; $\mathrm{CE}$ : external carotid artery; AOc: occipital artery; AM: maxillary artery; MM: middle meningeal artery. MMA: accessory middle meningeal artery; MMF: middle meningeal artery frontal branch; MMP: middle meningeal artery parietal branch; $C A$ : anterior cerebral artery; $C M$ : middle cerebral artery; $\mathrm{CP}$ : posterior cerebral artery.
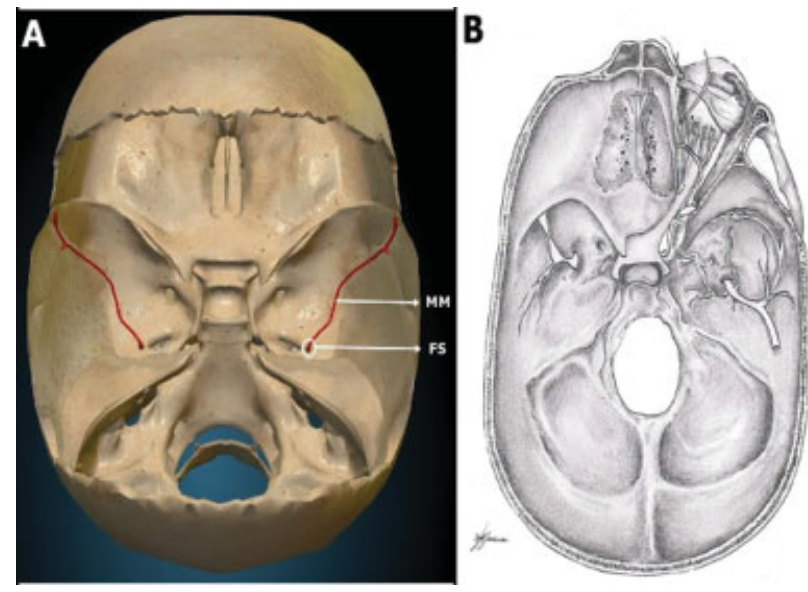

Fig. 6 Top view. (A) - bilateral middle cranial fossa, with folded parietal bone, representing the MM ascending the FS and following the middle fossa. (B) - 2D schematic drawing showing the anterior, middle and posterior fossa of the skull. FS: spinous foramen; MM: middle meningeal artery.

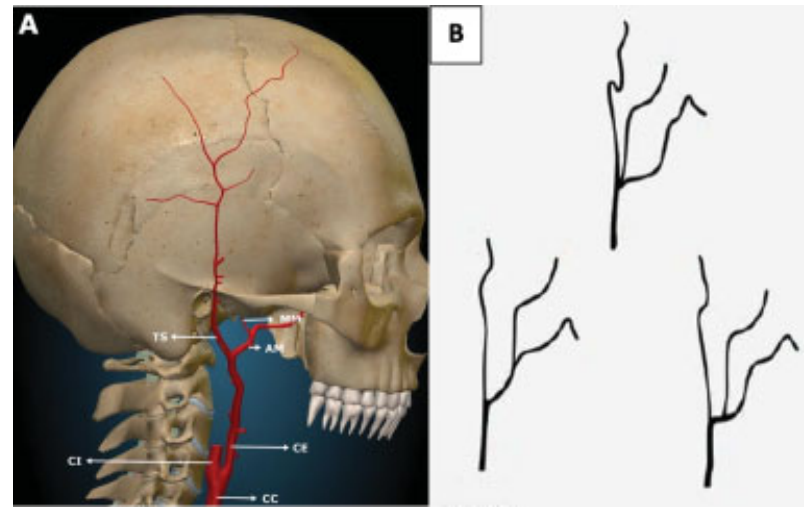

Fig. 7 Side view. Anatomical variations of the middle meningeal artery in the extracranial segment. A-branching distal to the maxillary artery (AM). B - schematic representation of MMA variation. 

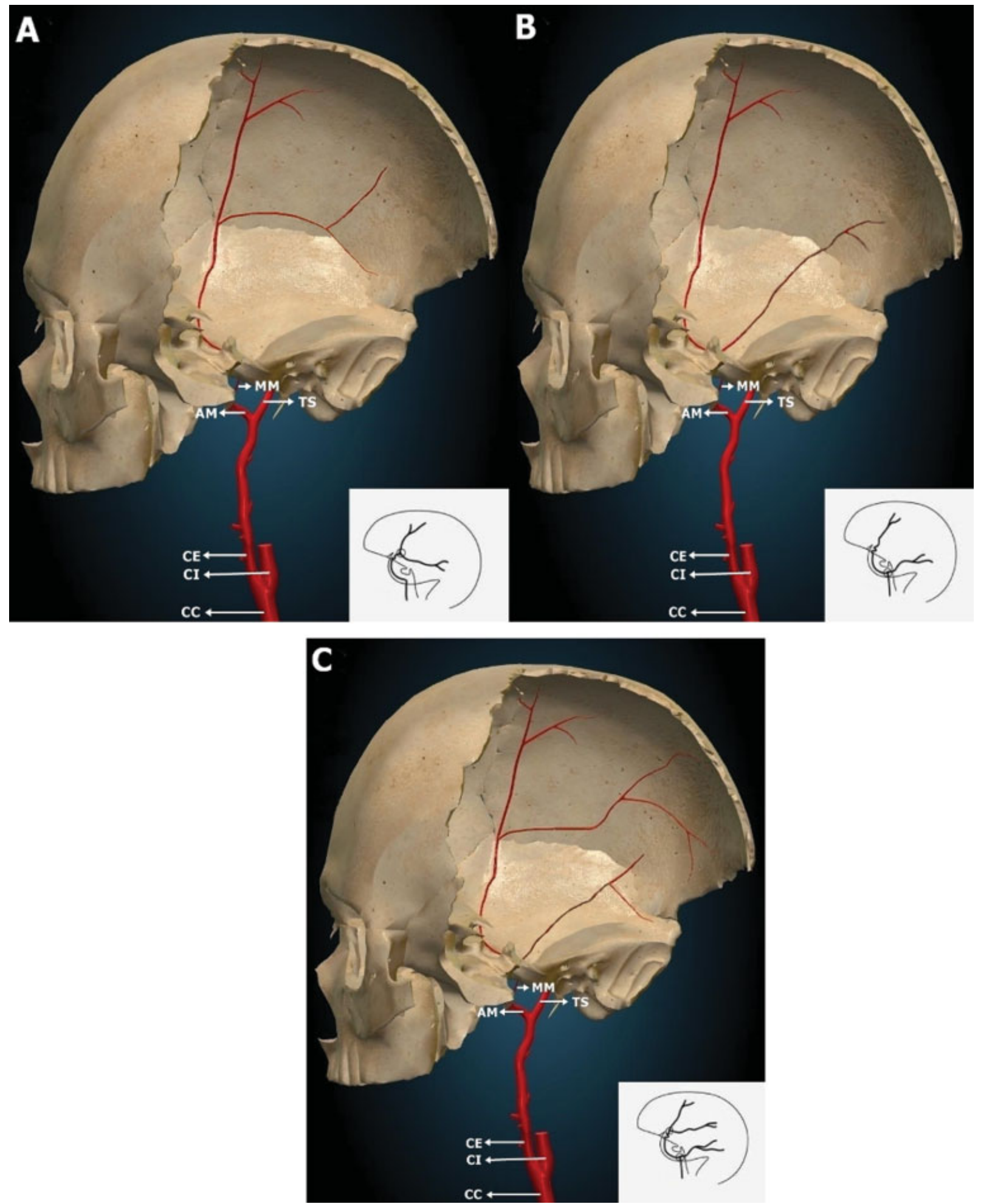

Fig. 8 Representation of common anatomical variations of the middle meningeal artery (MM) after penetrating the skull through the spinous foramen (intracranial segment). A - bifurcation in the ore, $25 \%$ of the cases; B - bifurcation when leaving the spinous foramen (FS), $50 \%$ of the cases (most common); C- association of the bifurcation in the ore with the exit of the FS, $13 \%$ of cases.

pontocerebellar angle, through branches that run under the upper petrosal sinus to achieve that angle.

The petrosquamous branch, through its basal tentorial branches, runs posterolaterally along the petrosquamous sulcus of the temporal bone and gives blood supply for the basal $2 / 3$ of the cerebellar tent. Besides, it come up with branches to the posterior fossa and may even irrigate lateral sinus fistulas. ${ }^{21}$

Finally, it divides into two terminal branches: 1) the frontal branch, which irrigates the bones that constitute 
the anterior cranial fossa and the anterior part of the middle cranial fossa. Nevertheless, this branch may also originate the marginal artery of the cerebellum tent, which is responsible for the irrigation of the anterosuperior third of the cerebellum tent, contributing to supply the trochlear and oculomotor in the cavernous sinus roof; and 2) the posterior branch, which runs away more horizontally towards the posterior segment, supplying the supratentorial portion of the posterior cranial fossa and the posterior region of the middle cranial fossa. Perforating branches, belonging to the posterior and anterior branches, cross the arterial sulcus and originate abundant lateral pathways that also reach the dipole and, eventually, the outer skull layers. ${ }^{18,20-22}$

There are also 1) the ganglion branches or the trigeminal ganglion branch, which provide blood to the trigeminal ganglion and associated roots; 2 ) the upper tympanic artery, which runs through the semicanal to the tensor tympani muscle, supplying the muscle itself as well as the mucosa lining the semicanal; 3) temporal branches, which traverse tiny foramens in the greater wing of the sphenoid bone, anastomosing with the deep temporal arteries; and, finally, 4) an orbital branch, which anastomoses with the recurrent meningeal branch of the lacrimal artery. ${ }^{18,19,23}$

The accessory meningeal artery is a branch that can comes from the extracranial MMA segment or from the internal maxillary $\operatorname{artery}^{22}$ (-Fig. 4B, - Fig. 5B). It promotes the vascularization of the pterygoid, veli palatine tensor muscle, as well as to the auditory chanel. ${ }^{19}$ It exhibits an endocranial branch, namely cavernous branch, which crosses over the foramen ovale or the Versalius foramen, and contributes to the irrigation of the mandibular branch of the trigeminal nerve, the dura adjacent to the thallus saddle and the semilunar ganglion. ${ }^{24,25}$ Their extracranial branches are also valuable, since they are involved in skull base diseases such as angiofibromas, dural fistulas, and meningiomas, originated from anastomoses with the ascending, mandibular, pterygovian arteries and ascending and descending palatine arteries. ${ }^{21}$

The posterior superior alveolar artery commonly appears just before the maxillary artery entry in the pterygopalatine fossa, and often shares a communal trunk with the infraorbital artery, but it may also arise from the MMA. The reason for that phenomenon could be the altered return of the plexiform anastomoses between the stapedial artery and the maxillary artery, resulting in the fusion of the posterior superior alveolar artery with the medial meningeal artery. ${ }^{7}$ This feature bring severe surgical implications to the procedures involving intransantral radical maxillectomy, lateral approach of the infratemporal fossa and pterygopalatine, manipulations of the medial and anterior parts of the skull base (including the management of oropharynx and nasopharynx lesions), as well as to the dorsocaudal management of the medial skull base. $2,26,27$

It has been established that the Krönlein method, the surgical procedure based on the orbit approach through the temporal fossa, mobilizing the malar bone, may constitute the simplest way to localize the main trunk of the MMA, since there is lack of accurate topographic information defining its pathway. ${ }^{22,27,28}$ To localize the frontal branch, two imaginary lines should be used: an upper horizontal line, guided by the top edge of the orbit, and an anterior vertical line, which crosses the middle of the zygomatic arch. To establish the location of the parietal branch, one must find the intersection of two lines: an upper horizontal line and a posterior and vertical line, the latter running immediately beside the back of the mastoid process. ${ }^{20}$

Furthermore, several authors have shown that the anterior branch of the MMA, or the pterion segment, which passes by the pterion and arises along the coronal suture, may be surrounded by a canal-like bone structure. ${ }^{5,29-31}$ This canal, which is found in between 49 and $75 \%$ of the skulls, ${ }^{4,32}$ is formed mainly when the anterior MMA branch, which runs through the dura of the sphenoidal fontanelle, is surrounded by bone in the closure of the fontanelle during bone formation. It is always located around the pterion, posterior to the coronal suture, at a lower level of the superior temporal bounder, but never below the frontal bone. In cases where the anterior MMA branch is located in a bone canal, the MMA may be damaged during removal of the bone flap during neurosurgical surgeries. Therefore, to preserve its integrity during frontotemporal craniotomy, it must be exposed by a perforation around the pterion. ${ }^{30}$

In this regard, Kornieieva et al. demonstrated that the morphological features of the MMA may be related to the individual characteristics of the skull. Patients showing a mesocephalic skull shape provide the most favorable anatomical conditions for the endovascular approach of MMAassociated pathologies, whereas the brachycephalic skull shape is characterized by a more negative anatomical prognosis. This makes this latter kind of formation undesirable for MMA interventional manipulations, being the conventional surgery the preferred method in these cases. ${ }^{8}$

The embryogenic MMA origin consists of the stapedial artery, the main trunk derived from the hyoid artery at the level of the stapes, which is divided into maxillofacial and supraorbital divisions. Together, these branches supply the orbit and provide the intracranial MMA portion. ${ }^{19,33}$ After the ophthalmic artery assimilates the intraorbital branches of the stapedial artery, its proximal and retro-orbital branches evolve and are assimilated by the intracranial MMA portion. Subsequently, the branches belonging to the maxillofacial division of the stapedial artery are absorbed by the developing external carotid artery and originate the internal maxillary artery (including the extracranial MMA segment). At this step, the proximal (trunk) segment of the stapedial artery involutes around the $3^{\text {rd }}$ month of gestation, and the remaining structure becomes the tympanic MMA branch. ${ }^{3,33-38}$ Accordingly, there are anatomical variations that can be explained by this particular embryology. Among the anomalous origins of the MMA is the posteroinferior cerebellar artery. ${ }^{39}$ The embryological basis for this variation is still unknown, but, from a neurosurgical point of view, this knowledge will certainly avoid destruction of blood supply to structures located at the posterior cranial fossa during MMA embolization. ${ }^{19}$ Another rare origin comprises the basilar artery or one of its branches. ${ }^{23}$ The precise origin location is 


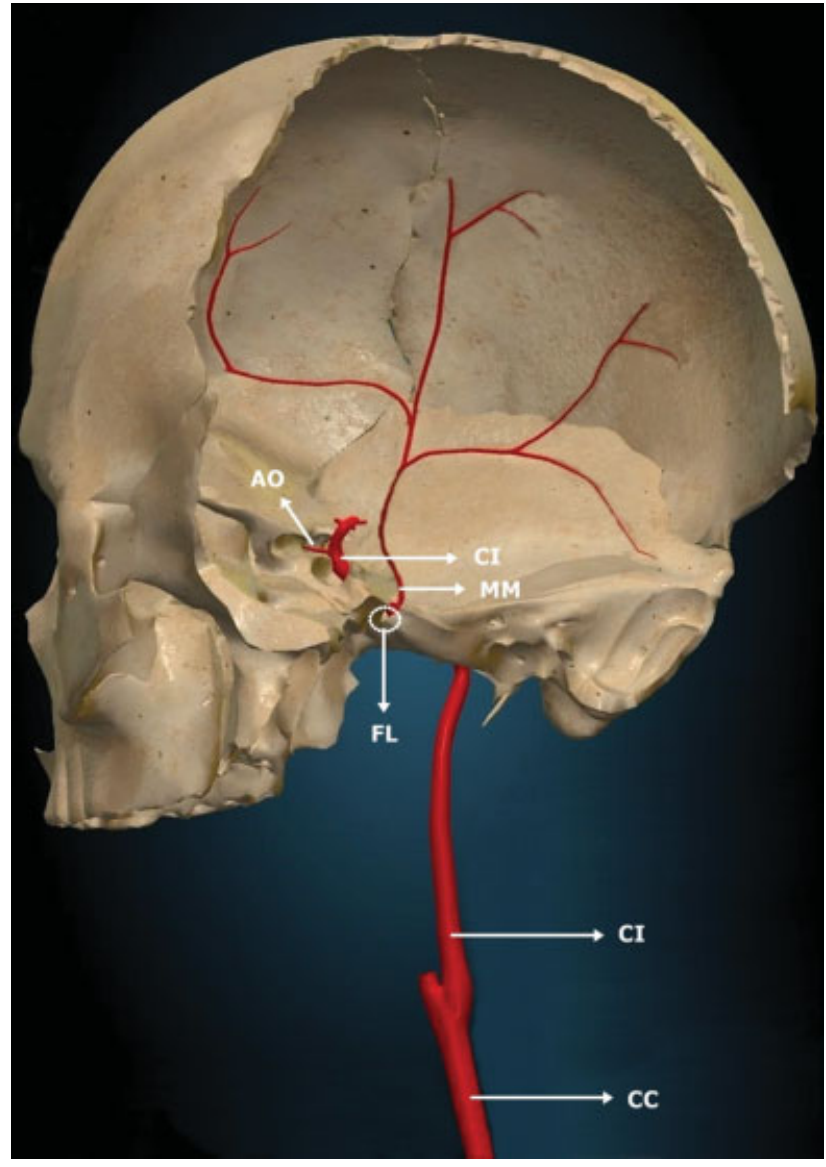

Fig. 9 Side view. Parietal, occipital, zygomatic and temporal bone folded. Evidence of the internal carotid artery. Anatomical variation of the middle meningeal artery (MM). Branch adjacent to the lacerated foramen (FL). CC: common carotid artery; CE: external carotid artery; $\mathrm{Cl}$ internal carotid artery; AO: ophthalmic artery.

always speculative, but it can be associated with persistent anastomosis around the trigeminal ganglion, as well as between the intracranial elements of the stapedial artery and of the lateral pontine artery. ${ }^{19}$

A more common variant is the MMA originated from the internal carotid artery, which occurs close to the lacerated foramen ${ }^{19}$ (- Fig. 9). The MMA may be generated from the extradural portion of the carotid siphon, a feature that is possibly explained, under the embryological point of view, as an aberrant origin (more distal or more caudal) of the hyoid artery from the internal carotid artery. In this case, the union between the hyoid artery with the remaining parts of the first branchial arch, to form the stapedial artery, does not occur, or occurs unrelated to the stapes level. This abnormality is characterized, therefore, by the absence of an undeveloped extracranial MMA. Another possible origin for the MMA is the petrous segment of the internal carotid artery. The basis of this anomaly is the persistence (defective involution) of the embryonic stapedial artery. ${ }^{40}$ In this case, the internal carotid artery runs inside the carotid canal along with the internal carotid artery, and then enters the lacerated foramen, without going through the middle ear cavity or perforating the stapes. When it reaches the lacerated foramen, it crosses the cavernous sinus just below the trigeminal ganglion. Subsequently, it follows a regular course, being divided into posterior and anterior branches. ${ }^{41}$

Finally, the MMA may also originate from the ophthalmic artery, which comes, after the assimilation of branches from the supraorbital segment of stapedial artery (that is, the extraocular and intraorbital branches), by the early ophthalmic artery, which initially only fills the eyeball. This feature occurs due to a development failure of the intraorbital proximal branches and of the retro-orbital stapedius, so the intracranial segment of the MMA remains connected to the intraorbital branches of the stapes. Besides the involution failure of the maxillofacial portion of the stapedial artery, the extracranial MMA portion is not formed. ${ }^{40}$

The remaining anatomical variations reported in the literature account for cases in which the MMA enters the middle cranial fossa through the foramen ovale, close to the mandibular nerve (as long as the spine foramen is absent), ${ }^{41,42}$ being originated at the third part of the maxillary artery (pterygopalatine). ${ }^{43}$ In this case, the MMA reaches the median cranial fossa by the lateral extremity of the superior orbital cleft. The MMA can also be generated from the ascending pharyngeal artery, crossing the lateral margin of the superior orbital fissure or through the meningo-orbitary foramen of the greater wing of the sphenoid bone, as a branch of the persistent stapedial artery. ${ }^{44-46}$

The persistent stapedial artery generally originates from the petrous segment of the internal carotid artery. ${ }^{47,48}$ It enters anteromedially into the hypotympanum, running next to the promontory. Then, it goes cranially through the stapes obturator foramen, reaching the facial canal by dehiscence, just behind the cochleariform process, going subsequently to the middle cranial fossa. ${ }^{49} \cdot{ }^{50-52}$ Their anastomotic branches enter the orbit through the superior orbital fissure (meningo-ophthalmic artery) or through a foramen on the greater wing of the sphenoid bone, called meningo-orbital foramen, ${ }^{50}$ Hyrtl canal, or cranio-orbital foramen. ${ }^{50,52}$ The branch that goes through the foramen is known as the meningolacrimal artery. Furthermore, it is worth mentioning that the vascular system of the MMA is commonly confounded with the anterior vascular network that goes by the superior orbital fissure (sphenoidal artery) and through the meningo-orbital foramen (meningolacrimal artery). ${ }^{50}$

\section{Clinical Considerations}

The MMA that comes from the dura mater is incorporated in the groove or drip of the internal surface of the skull and presents a straight, direct path. ${ }^{8}$ Pseudoaneurysm can be formed when a hematoma or a secondary connective tissue formation occurs following an injury to the temporal area. According to Kawaguchi et al., ${ }^{53} \sim 70 \%$ of the MMA traumatic pseudoaneurysm cases are related to trauma fractures affecting the temporal region. Post-traumatic MMA pseudoaneurysms can suddenly rupture after repair of the brain lesion, and the time elapsed between the initial lesion and the aneurysm development varies from 4 to 30 days. ${ }^{53-55}$

Therefore, the mortality can be notably reduced when the postpseudoaneurysm is promptly diagnosed and treated. ${ }^{56}$ 
The MMA may, therefore, be important for postsurgical revascularization, except for indirect shunt, such as the encephalo-dura-arterio-synagiosis. It stimulates collateral circulation between the temporal muscle and the dura mater, leading to angiogenesis. ${ }^{1}$ The MMA is also frequently used as an endovascular embolization for conditions such as FAVD, pseudoaneurysm, true aneurysm, and meningioma. ${ }^{57,58}$ Suzuky et al. ${ }^{59}$ reported that MMA endovascular embolization is currently the most effective method to acute bleeding. To avoid complications in open cranial surgeries, endovascular access is the choice procedure due to the extracranial origin and to the direct course of the MMA to the cranial cavity. ${ }^{60}$

The rate of acute epidural hematomas and posttraumatic pseudoaneurysms of the MMA subjected to nonconventional endovascular therapies is increasing in emergency room settings. ${ }^{58,59}$ As in post-traumatic MMA pseudoaneurysm, cranial fracture is commonly associated to fistulas communicating the parallel middle meningeal vein and the diploic vein. ${ }^{54,55}$ The MMA FAVD represents the second most frequent traumatic arteriovenous dural fistula originated from posttraumatic carotid-cavernous sinus fistula. The clinical symptoms include consciousness changes and headache, and resection by craniotomy and embolization are the alternatives therapies. ${ }^{61}$

Migraine is generally considered a neurovascular disorder characterized by unilateral, pulsatile headache pain, associated with photophobia, nausea, vomiting, and dizziness. According to the described pathophysiology, vasodilatation lead by vasodilator agents, such as the peptide related to the gene of calcitonin, nitric oxide and serotonin, may constitute the mechanism underlying the stimulation of the cerebral and middle meningeal arteries. ${ }^{62}$

Furthermore, during cranial surgery, to avoid visible damage to a possible anastomosis between the MMA and the ophthalmic artery pathway to the ethmoidal artery, the MMA needs to be preserved. Meningeal vessels attach to the inner part of the bony vault of the skull and, in case they are fractured, the MMA can be damaged, causing epidural hematoma in up to $85 \%$ of the cases. ${ }^{63}$ Patients with cranial fractures that affect the meningeal vessels are more commonly affected by epidural hematomas and recurrent episodes of hematoma-related bleeding, so damage to the MMA may also be involved in recidivated chronic subdural hematoma. ${ }^{31}$ Finally, the MMA also has an important impact in the treatment and prognosis of MMD. As already known, MMD consists of an unusual cerebrovascular disorder featuring progressive obstruction of the last portion of the internal carotid artery and its main branches within the Willis circle (mainly middle and anterior cerebral arteries), resulting in the development of a vascular network (Moya-Moya vessels) in the brain. ${ }^{31,64-67}$ It is therefore crucial to know the surgical anatomy of the MMA around the pterion, to keep intact its anterior branch during the surgical MMD management surgery. Not surprisingly, in MMD patients, the anterior branch may potentially originate essential collateral branches that provide blood supply to the anterior cerebral artery area. ${ }^{31}$ In fact, the MMA plays an essential role in the progress and compensation of collateral circulation in MMD. In the case of recurrent chronic subdural hematoma, when conventional surgery and drainage fail, MMA embolization may constitute an alternative. Finally, we consider that every neurosurgeon must know the anatomy of the MMA sufficiently to correlate it with the diagnosed pathology, thus obtaining treatment effectiveness and preventing iatrogenies.

\section{Conclusion}

The MMA is a clinically significant anatomical structure to be considered during the treatment of neurosurgical diseases. It is inserted into a skull sulcus, and iatrogenic factors or trauma may lead to pseudoaneurysms, MMA DAVF or damage. In addition, true MMA aneurysms can develop in response to increased hemodynamic stress. Surgical or endovascular removal can efficiently treat true aneurysms, pseudoaneurysms, and DAVF.

\section{Conflict of Interests}

The authors have no conflict of interests to declare.

\section{Acknowledgments}

The main authors would like to thank Professor Silvia Graciela Ruginsk of the School of Medicine of the Universidade Federal de Alfenas for her participation and notable dedication and continuous support in the English version of the present paper.

\section{References}

1 Adachi B. Das arterien system der Japaner. Kyoto. Verlag der Kaiserlich-Japan Universität zu Kyoto 1928(47-51):91-94

2 Krmpotic-Nemanic J, Draf W, Helms J. Surgical anatomy of head and neck. Berlin: Springer-Verlag; 1985183198-200

3 Lasjaunias P, Moret J, Manelfe C, Théron J, Hasso T, Seeger J. Arterial anomalies at the base of the skull. Neuroradiology 1977; 13(05):267-272

4 Harthmann da Silva T, Ellwanger JH, Silva HT, et al. Morphometric analysis of the middle meningeal artery organization in humansembryological considerations. J Neurol Surg B Skull Base 2013;74 (02):108-112

5 Shimizu S, Hagiwara H, Utsuki S, Oka H, Nakayama K, Fujii K. Bony tunnel formation in the middle meningeal groove: an anatomic study for safer pterional craniotomy. Minim Invasive Neurosurg 2008;51(06):329-332

6 Akyuz M, Tuncer R. Multiple middle meningeal artery aneurysms associated with fistulous galenic arteriovenous malformation: a case report. Turk Neurosurg 2010;20(04):544-546

7 Kresimir Lukic I, Gluncic V, Marusic A. Extracranial branches of the middle meningeal artery. Clin Anat 2001;14(04):292-294

8 Kornieieva M, Hadidy A, Zhuravlova I. Variability of the Middle Meningeal Artery Subject to the Shape of Skull. J Neurol Surg B Skull Base 2015;76(06):451-458

9 Albert FK, Oldenkott P, Sigmund E. [Subarachnoid hemorrhage and intracerebral hematoma in injury of the middle meningeal artery (aneurysma spurium)]. Zentralbl Neurochir 1989;50(34):153-156

10 Hoskin KL, Zagami AS, Goadsby PJ. Stimulation of the middle meningeal artery leads to Fos expression in the trigeminocervical nucleus: a comparative study of monkey and cat. J Anat 1999;194 (Pt 4):579-588 
11 Ustün ME, Büyükmumcu M, Şeker M, Karabulut AK, Uysal II, Ziylan T. Possibility of middle meningeal artery-to-petrous internal carotid artery bypass: an anatomic study. Skull Base 2004;14 (03):153-156

12 Ustun ME, Buyukmumcu M, Ulku CH, Guney O, Salbacak A. Transzygomatic-subtemporal approach for middle meningealto-P2 segment of the posterior cerebral artery bypass: An anatomical and technical study. Skull Base 2006;16(01):39-44

13 Kainz J, Stammberger $H$. The roof of the anterior ethmoid: a place of least resistance in the skull base. Am J Rhinol 1989;3(04):191-199

14 Newton TH. The anterior and posterior meningeal branches of the vertebral artery. Radiology 1968;91(02):271-279

15 Penfield W, McNaughton F. Dural headache and innervation of the dura mater. Arch Neurol Psychiatry 1940;44(01):43-75

16 Maeda S, Aizawa Y, Kumaki K, Kageyama I. Variations in the course of the maxillary artery in Japanese adults. Anat Sci Int 2012;87(04):187-194

17 Salamon G, Faure J, Raybaund C, Grisoli F. The External Carótida Internal. In Radiology of the skull brain. Angiography In: Newton, Potts DG. Mosby CVSaint Louis1974:1246-1275

18 Goss CM. Gray Anatomia. 29. ed. Rio de JaneiroGuanabara Koogan 1977

19 Royle G, Motson R. An anomalous origin of the middle meningeal artery. J Neurol Neurosurg Psychiatry 1973;36(05):874-876

20 Plummer SC. III. Research on the surgical anatomy of the middle meningeal artery. Ann Surg 1896;23(05):540-572

21 Vasconcelos C, Xavier J, Almeida-Pinto J, Cruz R. Vascularização da base do crânio-revisão da literatura e casos ilustrativos. Acta Med Port 2001;14(01):33-42

22 Chmielewski P, Skrzat J, Walocha J. Clinical importance of the middle meningeal artery. Folia Med Cracov 2013;53(01):41-46

23 Shah QA, Hurst RW. Anomalous origin of the middle meningeal artery from the basilar artery: a case report. J Neuroimaging 2007;17(03):261-263

24 Lasjaunias P, Théron J. Radiographic anatomy of the accessory meningeal artery. Radiology 1976;121(01):99-104

25 Vitek JJ. Accessory meningeal artery: an anatomic misnomer. AJNR Am J Neuroradiol 1989;10(03):569-573

26 Krmpotić-Nemanić J Anatomie, Variationen und Missbildungen der Gefässe im Kopf- und Halsbereich. Arch Otorhinolaryngol 1978;219(02):285-305

27 Allen WE III, Kier EL, Rothman SLG. The maxillary artery in craniofacial pathology. Am J Roentgenol Radium Ther Nucl Med 1974;121(01):124-138

28 Komarnitki I, Andrzejczak-Sobocińska A, Tomczyk J, Deszczyńska $\mathrm{K}$, Ciszek B. Clinical anatomy of the auriculotemporal nerve in the area of the infratemporal fossa. Folia Morphol (Warsz) 2012;71 (03):187-193

29 Fujimoto M, Otsuka N, Ezure H, Moriyama H, Inoue Y, Mori R. Intracranial Bony Canal of the Middle Meningeal Artery - Morphological and Histological Analysis. Okajimas Folia Anat Jpn 2017;93(04):119-125

30 Ma S, Baillie LJ, Stringer MD. Reappraising the surface anatomy of the pterion and its relationship to the middle meningeal artery. Clin Anat 2012;25(03):330-339

31 Hori S, Kashiwazaki D, Akioka N, et al. Surgical anatomy and preservation of the middle meningeal artery during bypass surgery for moyamoya disease. Acta Neurochir (Wien) 2015; 157(01):29-36

32 Manjunath KY. Anomalous origin of the middle meningeal arteryA review. J Anat Soc India 2001;50(02):179-183

33 Carvalho BV, Gaiotti JO, Diniz RLFC, Ribeiro MA, Motta EGPC, Moreira W. Persistência da artéria estapedial: relato de caso. Radiol Bras 2013;46(03):184-186

34 Dilenge D, Ascherl GF Jr. Variations of the ophthalmic and middle meningeal arteries: relation to the embryonic stapedial artery. AJNR Am J Neuroradiol 1980;1(01):45-54
35 Ellwanger JH, Campos Dd. Abnormality of the Foramen Spinosum due to a Variation in the Trajectory of the Middle Meningeal Artery: A Case Report in Human. J Neurol Surg Rep 2013;74(02): 73-76

36 Salem MM, Fusco MR, Dolati P, et al. Middle meningeal artery arising from the basilar artery. J Cerebrovasc Endovasc Neurosurg 2014;16(04):364-367

37 Da Silva TH, Ellwanger JH, Da Rosa HT, De Campos D. Origins of the middle meningeal artery and its probable embryological mechanism-A review. Braz J Morphol Sci 2013;30(02):69-72

38 Gray H. In: Gray's Anatomy: The Anatomical Basis of Clinical Practice. 39th ed. Edinburgh: Elsevier Churchill Livingstone; 2005

39 Kuruvilla A, Aguwa AN, Lee AW, Xavier AR. Anomalous origin of the middle meningeal artery from the posterior inferior cerebellar artery. J Neuroimaging 2011;21(03):269-272

40 Kawai K, Yoshinaga K, Koizumi M, Honma S, Tokiyoshi A, Kodama $\mathrm{K}$. A middle meningeal artery which arises from the internal carotid artery in which the first branchial artery participates. Ann Anat 2006;188(01):33-38

41 Chandler SB, Derezinski CF. The variation of the middle meningeal artery within the middle cranial fossa. Anat Rec 1935;62:309-320

42 Nikolova SY, Toneva DH, Yordanov YA, Lazarov NE. Absence of foramen spinosum and abnormal middle meningeal artery in cranial series. Anthropol Anz 2012;69(03):351-366

43 Low FN. An anomalous middle meningeal artery. Anat Rec 1946; 95:347-351

44 Moret J, Lasjaunias P, Vignaud J, Doyon D. Participation de l'artère méningée moyenne à la vascularisation de la fosse postérieure. Neuroradiology 1978;16(01):306-307

45 McLennan JE, Rosenbaum AE, Haughton VM. Internal carotid origins of the middle meningeal artery. The ophthalmic-middle meningeal and stapedial-middle meningeal arteries. Neuroradiology 1974;7(05):265-275

46 Kwiatkowski J, Wysocki J, Nitek S. The morphology and morphometry of the so-called "meningo-orbital foramen" in humans. Folia Morphol (Warsz) 2003;62(04):323-325

47 Hitier M, Zhang M, Labrousse M, Barbier C, Patron V, Moreau S. Persistent stapedial arteries in human: from phylogeny to surgical consequences. Surg Radiol Anat 2013;35(10):883-891

48 Baltsavias G, Kumar R, Valavanis A. The pharyngo-tympanostapedial variant of the middle meningeal artery. A case report. Interv Neuroradiol 2012;18(03):255-258

49 Thiers FA, Sakai O, Poe DS, Curtin HD. Persistent stapedial artery: CT findings. AJNR Am J Neuroradiol 2000;21(08):1551-1554

50 Diamond MK. Homologies of the meningeal-orbital arteries of humans: a reappraisal. J Anat 1991;178:223-241

51 Georgiou C, Cassell MD. The foramen meningo-orbitale and its relationship to the development of the ophthalmic artery. J Anat 1992;180(Pt 1):119-125

52 Erturk M, Kayalioglu G, Govsa F, Varol T, Ozgur T. The cranioorbital foramen, the groove on the lateral wall of the human orbit, and the orbital branch of the middle meningeal artery. Clin Anat 2005;18(01):10-14

53 Kawaguchi T, Kawano T, Kaneko Y, Ooasa T, Ooigawa H, Ogasawara $\mathrm{S}$. Traumatic lesions of the bilateral middle meningeal arteriescase report. Neurol Med Chir (Tokyo) 2002;42(05):221-223

54 Grandhi R, Zwagerman NT, Lee P, Jovin T, Okonkwo DO. Iatrogenic pseudoaneurysm of the middle meningeal artery after external ventricular drain placement. J Neuroimaging 2015;25(01): 140-141

$55 \mathrm{Ko} \mathrm{JH,} \mathrm{Kim} \mathrm{YJ.} \mathrm{Traumatic} \mathrm{pseudoaneurysm} \mathrm{of} \mathrm{the} \mathrm{middle} \mathrm{menin-}$ geal artery with an arteriovenous fistula on a non-fractured site. Interv Neuroradiol 2014;20(03):352-356

56 Wang $\mathrm{CH}$, Lee $\mathrm{HC}$, Cho DY. Traumatic pseudoaneurysm of the middle meningeal artery: possible indicators for early diagnosis in the computed tomography era. Surg Neurol 2007;68(06): 676-681 
57 Mewada T, Ohshima T, Yamamoto T, Goto S, Kato Y. Usefulness of Embolization for Iatrogenic Dural Arteriovenous Fistula Associated with Recurrent Chronic Subdural Hematoma: A Case Report and Literature Review. World Neurosurg 2016;92:584.e7-584. e10

58 Shah QA, Hurst RW. Endovascular Treatment of a Traumatic Pseudo Aneurysm of the Middle Meningeal Artery. Radiol Case Rep 2015;1(03):73-76

59 Suzuki S, Endo M, Kurata A, et al. Efficacy of endovascular surgery for the treatment of acute epidural hematomas. AJNR Am J Neuroradiol 2004;25(07):1177-1180

60 Araujo JL, Aguiar UdoP, Todeschini AB, Saade N, Veiga JCE. Epidemiological analysis of 210 cases of surgically treated traumatic extradural hematoma. Rev Col Bras Cir 2012;39(04): 268-271

61 Friedman AH. Etiologic factors in intracranial dural arteriovenous malformations. Dural Arteriovenous Malformations Park Ridge, AANS. 1993:35-47
62 Nagata E, Moriguchi H, Takizawa S, Horie T, Yanagimachi N, Takagi $\mathrm{S}$. The middle meningial artery during a migraine attack: 3T magnetic resonance angiography study. Intern Med 2009;48 (24):2133-2135

63 Bruner E, Sherkat S. The middle meningeal artery: from clinics to fossils. Childs Nerv Syst 2008;24(11):1289-1298

64 Lasjaunias P, Berenstein A, ter Brugge KG. Clinical Vascular Anatomy and Variations. Springer Science \& Business Media. 2001. Doi: $10.1007 / 978-3-662-10172-8$

65 Hayashi N, Kubo M, Tsuboi Y, et al. Impact of anomalous origin of the ophthalmic artery from the middle meningeal artery on selection of surgical approach to skull base meningioma. Surg Neurol 2007;68(05):568-571, discussion 571-572

66 Kuroda S, Houkin K. Moyamoya disease: current concepts and future perspectives. Lancet Neurol 2008;7(11):1056-1066

67 Suzuki J, Takaku A. Cerebrovascular "moyamoya" disease. Disease showing abnormal net-like vessels in base of brain. Arch Neurol 1969;20(03):288-299 